DLR für Luft- und Raumfahrt e.V.

in der Helmholtz-Gemeinschaft

This is a post-peer-review, pre-copyedit version of the article:

Steigenberger P., Thölert S., Montenbruck O. (2019): Flex power on GPS Block IIR-M and IIF, GPS Solutions, Vol. 23, No. 8, DOI: 10.1007/s10291-018-0797-8

The final authenticated version is available online at: http://dx.doi.org/10.1007/s10291-018-0797-8 


\title{
Flex power on GPS Block IIR-M and IIF
}

\author{
Peter Steigenberger*a ${ }^{*}$ Steffen Thölert ${ }^{\mathrm{b}}$ and Oliver Montenbruck ${ }^{\mathrm{a}}$ \\ ${ }^{\mathrm{a}}$ German Space Operations Center (GSOC), Deutsches Zentrum für Luft-und Raumfahrt (DLR), Münchener Straße 20, D-82234 Weßling, \\ Germany \\ ${ }^{b}$ Institute of Communications and Navigation (IKN), Deutsches Zentrum für Luft-und Raumfahrt (DLR), Münchener Straße 20, D-82234 \\ Weßling, Germany
}

\begin{abstract}
GPS Block IIR-M and Block IIF satellites have the capability to redistribute transmit power between individual signal components. This so-called flex power can be used for increased protection against jamming and was already demonstrated in September 2010. Since January 2017, a geographically driven flex power mode is enabled on ten Block IIF satellites. It is visible in carrier-to-noise density ratio observations of ground-based GPS receivers as well as differential code bias estimates between the L1 C/A- and P(Y)-code signals. Measurements with a $30 \mathrm{~m}$ high-gain antenna revealed a $2.5 \mathrm{~dB}$ increase of the L1 C/A and $\mathrm{P}(\mathrm{Y})$ power when the L1 M-code is regularly disabled.

During four days in April 2018, a different flex power mode was put in place for all healthy Block IIR-M and IIF satellites. Carrier-to-noise density observations of geodetic GPS receivers show an increase of about $11 \mathrm{~dB}$ for combined L1+L2 P(Y)code power. The high-gain antenna measurements consistently show an increase of $\mathrm{P}(\mathrm{Y})$-code power by 5 and $6 \mathrm{~dB}$ for $\mathrm{L} 1$ and L2, respectively, due to deactivation of the military M-code on both frequencies. Finally, during three days in April/May 2018, another type of flex power was observed: for 11 hours of each of the three days, another geographically driven flex power mode was enabled but above a different area than the flex power mode mentioned above. Next to measurements of signal spectra, inphase/quadrature components, and signal power with a highgain antenna, the impact of flex power on the tracking and measurements of geodetic receivers is investigated.
\end{abstract}

Keywords: Global Positioning System; transmit power; carrier-to-noise density ratio; differential code biases

\section{Introduction}

Satellites of the Global Positioning System (GPS) transmit navigation signals for civil and military users in dedicated frequency bands, namely L1 at $1575.42 \mathrm{MHz}, \mathrm{L} 2$ at $1227.60 \mathrm{MHz}$, and L5 at $1176.45 \mathrm{MHz}$. All satellites transmit the civil C/A-code on L1 and the military (encrypted) P(Y)-code on L1 and L2. The newer Block IIR-M satellites (Rajan and Tracy, 2002; Betz, 2016) in addition transmit the civil L2C signal on L2 and the military M-code on L1 and L2. The L5 signal is only supported by the latest generation of Block IIF satellites (Fisher

*凶 Peter Steigenberger: peter.steigenberger@dlr.de and Ghasemi, 1999). Usually, GPS satellites transmit their navigation signals with constant total power and power ratios. The transmit power has to fulfill the requirements of received minimum signal strength given in the interface specifications ISGPS-200J (2018) and IS-GPS-705E (2018) for the open service signals and the $\mathrm{P}(\mathrm{Y})$-code. Approximate values for the military M-code are given in Barker et al. (2000). Pre-launch groundbased measurements (Wu, 2002) as well as in-flight measurements with a high-gain antenna (Edgar et al., 2002; Steigenberger et al., 2018) showed that the actual transmit power is higher to guarantee the IS specifications under any circumstances.

However, a redistribution of transmit power between the different signals of the individual L1 and L2 frequency bands is possible on the Block IIR-M and IIF satellites to optimize operational constraints (Defense Science Board, 2005; Rajan and Irvine, 2005). In IS-GPS-200J (2018), this so-called flex power is described as follows: “... due to programmable power output capabilities of Block IIR-M and IIF SVs, under certain operational scenarios, individual signal components of Block IIR-M/IIF SVs may exceed the previously stated maximum but are not expected to exceed $-150 \mathrm{dBW}$ ", where SV stands for space vehicle.

Flex power has been demonstrated in a dedicated test campaign in September 2010. Jimenez-Banos et al. (2011) report an increase of about $10 \mathrm{~dB}$ in the $\mathrm{P}(\mathrm{Y})$-code carrier-to-noise density ratio $\left(C / \mathrm{N}_{0}\right)$ measurements of the Galileo Experimental Sensor Station (GESS) network. The C/A code power stayed constant, and the authors speculated that the increased $\mathrm{P}(\mathrm{Y})$ code power on all Block IIR-M satellites was due to a transfer of the complete M-code power, due to a total transmit power increase, or due to a change of the transmit antenna pattern.

In January 2017, a Notice Advisory to NAVSTAR Users (NANU 2017005) announced that that the "2nd Space Operations Squadron (2 SOPS) periodically conducts configuration changes on GPS satellites to assess current capabilities, validate future capabilities and ensure continued interoperability". Shortly after publication of this NANU, on 7 and 8 February 2017, an L1 transmit power redistribution for the seven operational Block IIR-M satellites occurred (Thoelert et al., 2018). The C/A-code power was increased by $2.4 \mathrm{~dB}$ and the $\mathrm{P}(\mathrm{Y})$ code by 0.1 to $0.6 \mathrm{~dB}$, whereas the M-code power was found to decrease by 1.2 to $1.7 \mathrm{~dB}$ depending on the determination method. The intermodulation product that does not contribute to the usable navigation signals was reduced by almost $4 \mathrm{~dB}$. 
However, the total transmit power of the Block IIR-M satellites stayed constant.

In this paper, three different kinds of flex power modes are discussed. The first one is almost permanently enabled since January 2017 on most Block IIF satellites resulting in increased L1 C/A and P(Y) transmit power over a dedicated area. A global flex power mode on L1 and L2 could be observed on four consecutive days in April 2017 for all healthy Block IIR-M and IIF satellites. Finally, an 11-hour regionally confined flex power mode occurred on three days end of April and beginning of May 2018. An overview of these different flex power modes is given in Table 1.

\section{Observations and analysis methods}

The impact of flex power is analyzed in terms of $\mathrm{C} / \mathrm{N}_{0}$ of ground-based receivers and high-rate differential code biases estimated from a global tracking network. Furthermore, selected satellites were observed with a $30 \mathrm{~m}$ high-gain antenna to reveal the power distribution of the different GPS signals during flex power.

\section{Carrier-to-noise density ratio}

GNSS observation files in the Receiver INdependent EXchange (RINEX) format version 3 (IGS RWG and RTCM, 2015) usually contain the carrier-to-noise density ratio of the individual signals as measured by the receiver. $\mathrm{C} / \mathrm{N}_{0}$ describes the ratio of the carrier power of a GNSS signal and the noise power in a 1$\mathrm{Hz}$ bandwidth. While essentially a measure of signal quality, it can also be used as an indicator of the received signal strength if the noise power can be assumed to remain constant. Due to different antenna gains, low noise amplifiers, and receiver-specific methods for estimating $\mathrm{C} / \mathrm{N}_{0}$ (Falletti et al., 2011), $\mathrm{C} / \mathrm{N}_{0}$ measurement from different stations may not be directly comparable. However, $\mathrm{C} / \mathrm{N}_{0}$ variations for a specific station may be used to sense and evaluate stepwise changes in transmit power.

$\mathrm{C} / \mathrm{N}_{0}$ observation data of a global network of GNSS tracking stations are freely provided by the International GNSS Service (IGS; Dow et al., 2009) and its Multi-GNSS Pilot Project (MGEX; Montenbruck et al., 2017). Geodetic GNSS receivers utilize semi-codeless techniques for the tracking of the encrypted P(Y)-code on the L1 and L2 frequencies (Woo, 2000). These techniques result in identical $\mathrm{C} / \mathrm{N}_{0}$ values for L1 and L2 denoted in the following by the RINEX observation codes S1W and $\mathrm{S} 2 \mathrm{~W}$. As several receiver types only provide the C/A-code on $\mathrm{L} 1$, the $\mathrm{L} 2 \mathrm{C} / \mathrm{N}_{0}$ of the semi-codeless $\mathrm{P}(\mathrm{Y})$-code tracking (S2W) will be considered in the following.

\section{Code and phase biases}

Flex power implies changes in the modulation of the GPS signals that affect the relative strength and, optionally, phasing of individual signal components. These changes may reflect themselves as modified biases in the pseudorange and carrier phase measurements. By way of example, early flex power tests have shown a jump in the $\mathrm{L} 2 \mathrm{C} / \mathrm{P}(\mathrm{Y})$ carrier phase difference causing substantial concerns among precise positioning service providers (InsideGNSS Team, 2010). Even though, the current GPS signal interface specification suggests that recent flex power changes should not have unintended detrimental impacts on the phase relation of open service and $\mathrm{P}(\mathrm{Y})$-signals, no independent confirmation of this fact has yet become available. To assess the impact of recent flex power campaigns on precise GPS users, we specifically investigate its impact on Differential Code Biases (DCBs), differential phase biases, and the Melbourne Wübbena combination.

DCBs describe delays between two GNSS code signals on the same or different frequencies originating from the satellite and receiver antennas and electronics (Håkansson et al., 2016). For GPS, the broadcast clock corrections as well as the IGS precise clock parameters are referred to the ionosphere-free linear combination of the L1 and L2 P(Y)-code signals. Therefore, single-frequency users or dual-frequency users utilizing other types of pseudorange observables have to estimate DCBs or apply them as corrections. DCBs also have to be considered if different types of pseudorange observations are used in a common analysis, e.g., L1 P(Y)-code and L1 C/A-code data, denoted by their RINEX 3 identifiers as C1C-C1W DCBs.

Receiver- and satellite-specific DCBs can be estimated from a geometry-free linear combination of single- or dual-frequency pseudorange observations. This linear combination eliminates all non-dispersive effects and only DCBs and the ionospheric delay remain. The electron content of the ionosphere can be either estimated or modeled. In the following, ionospheric maps provided by the European Space Agency (ESA) are used. The DCB estimation performed for the present study follows Montenbruck et al. (2014) but in addition provides a high-rate solution with a DCB parameter spacing of $15 \mathrm{~min}$. RINEX 3 data of 150 stations with 30 s sampling are used to estimate the following DCBs:

- L1 C/A- and L1 P(Y)-code: C1C-C1W

- L1 C/A- and L2 P(Y)-code: C1C-C2W

- L1 P(Y)- and L2 P(Y)-code: C1W-C2W

- L2 P(Y)-code and L2C: C2W-C2S, C2W-C2L, C2W-C2X

For $\mathrm{L} 2 \mathrm{C}$, three different types of observables are provided by the various receiver types depending on the tracked signal components: the moderate length code (C2S, Leica), the long length code (C2L, Septentrio) or a combined tracking of both $(\mathrm{C} 2 \mathrm{X}$, Javad and Trimble). For each of these tracking modes, a distinct $\mathrm{DCB}$ relative to the $\mathrm{C} 2 \mathrm{~W}$ measurements is determined.

In analogy with the intra-frequency code biases, changes in the intra-frequency phase biases can be monitored from differences of carrier phase measurements on common signal frequencies. In case of the L1 frequency, various receivers provide independent carrier phase measurements from C/A-code and $\mathrm{P}(\mathrm{Y})$-code (observation codes L1C-L1W). Likewise, independent carrier phase measurements from L2C and $\mathrm{P}(\mathrm{Y})$-code tracking on the L2 frequency are made available with observation codes L2S-L2W, L2L-L2W, or L2X-L2W depending on receiver type.

Finally, the Melbourne Wübbena (MW) linear combination (e.g., Hauschild, 2017) is considered. It is formed from dualfrequency code and carrier phase observations and aggregates the corresponding phase and group delays. The MW combination is widely applied in the context of ambiguity resolution and therefore of specific interest for high-precision GNSS applications. Potential changes due to flex power would specifically impact correction services for precise point positioning (e.g., Laurichesse et al., 2009). 
Table 1: Different types of flex power modes observed in 2017/2018.

\begin{tabular}{cccccl}
\hline Mode & Blocks & Band & Time frame & Geogr. distr. & Features \\
\hline I & IIF & L1 & since 27/2017 & $\begin{array}{c}\text { centered at } \\
41^{\circ} \mathrm{E} / 37^{\circ} \mathrm{N}\end{array}$ & C/A and P(Y) power increased by 2.5 dB \\
II & IIR-M + IIF & L1/L2 & $103-107 / 2018$ & global & $6 \mathrm{~dB} / 5 \mathrm{~dB} \mathrm{P}(\mathrm{Y})$ power increase on L1/L2 \\
III & IIR-M + IIF & L1/L2 & $\begin{array}{c}117,121,124 / 2018 \\
2: 00-13: 00 \mathrm{UTC}\end{array}$ & $\begin{array}{c}\text { centered at } \\
115^{\circ} \mathrm{W} / 40^{\circ} \mathrm{N}\end{array}$ & $\begin{array}{l}\text { Sum of L1+L2 P(Y) power increased by } \\
\text { 9 to } 11 \mathrm{~dB} ; \mathrm{IIR}-\mathrm{M}: \mathrm{L} 1 \mathrm{C} / \mathrm{A} \text { power } \\
\text { reduced by 2 to 3 dB }\end{array}$ \\
\hline
\end{tabular}

\section{High-Gain antenna measurements}

The German Space Operations Center (GSOC) of the German Aerospace Center (DLR) operates a $30 \mathrm{~m}$ dish antenna at its ground station in Weilheim (Germany). This antenna is regularly used by DLR's Institute of Communication and Navigation (IKN) for the analysis of GNSS signals (e.g., Thoelert et al., 2009, 2012a,b, 2014; Steigenberger et al., 2017). The antenna provides a gain of about $50 \mathrm{~dB}$ and supports spectrum, inphase/quadrature (IQ), and power measurements covering the lower and upper L-Band. For the present work, L1/L2 signal spectra of GPS satellites have been obtained to highlight the presence or amplitude variation of different modulations in the course of flex power tests. These are complemented by IQ constellation diagrams to illustrate the modulations and to evaluate the relative power distribution among individual signal components. A detailed summary of the current measurement setup is given in Thoelert et al. (2013).

\section{Mode I: increased L1 C/A- and $\mathrm{P}(\mathrm{Y})$-code power on Block IIF}

Starting on 27 January 2017, a regional flex power mode (denoted in the following as flex power mode I) was activated on the L1 frequency for ten out of twelve GPS Block IIF satellites. It is visible in $\mathrm{C} / \mathrm{N}_{0}$ and high-gain antenna observations and causes discontinuities of up to $0.8 \mathrm{~ns}$ in high-rate DCB estimates. This kind of flex power operations was temporarily disabled during the mid April global flex power campaign discussed in the next section but resumed thereafter and is still active at the time of writing (August 2018).

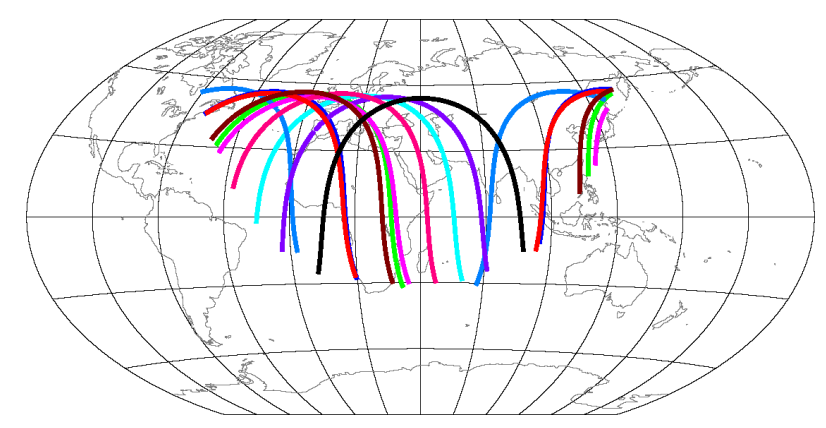

Fig. 1: Groundtracks of GPS Block IIF satellites with increased $\mathrm{S} 2 \mathrm{~W} \mathrm{C} / \mathrm{N}_{0}$ on 2 June 2018. Different colors indicate individual satellites.

\section{Carrier-to-noise density ratio}

$\mathrm{L} 1 \mathrm{C} / \mathrm{N}_{0}$ measurements for the $\mathrm{C} / \mathrm{A}$-code $(\mathrm{S} 1 \mathrm{C})$ and the $\mathrm{P}(\mathrm{Y})$ code (S1W) show regular changes by approximately 2 to $3 \mathrm{~dB}$. The periods with increased $C / \mathrm{N}_{0}$ have usually durations between $1^{\mathrm{h}} 14^{\mathrm{min}}$ and $7^{\mathrm{h}} 40^{\mathrm{min}}$. The resulting ground track pattern with increased $\mathrm{C} / \mathrm{N}_{0}$ is shown in Fig. 1. To maintain a constant geographical coverage, the transmit power switches are shifted by $-4^{\mathrm{min}}$ every day in accord with the GPS repeat period of $23^{\mathrm{h}} 56^{\mathrm{min}}$. Depending on the satellite's position within the constellation, one or two intervals with increased power occur within this period, as also visible in the DCB estimates in Fig. 2.

\section{Code and phase biases}

The C1C-C1W DCB estimates of eight Block IIF satellites with flex power mode I show discontinuities at a level of several tenths of ns (Fig. 2), which coincide in time with the $\mathrm{C} / \mathrm{N}_{0}$ shifts mentioned earlier. The DCB shifts as well as the geographical pattern shown in Fig. 1 have already been reported by Szilágyi et al. (2017). For two Block IIF satellites with flex power mode I, G066 and G068, no DCB changes are discernible within the noise level of the analysis. Overall, the DCB changes reflect a change in chip shapes caused by the flex power activation, which changes the tracking point of the correlator within the receiver. While a dependence of the DCB variations on the specific correlator type and architecture may be suspected (Hauschild and Montenbruck, 2016), such impacts could not be investigated within the present study. As such, the reported DCB changes represent an average over the different receivers in the IGS network used in our analysis.

None of the other DCB types listed above shows such shifts although it has to be mentioned that the noise of DCB estimates for signals on two different frequencies is higher compared to the $\mathrm{C} 1 \mathrm{C}-\mathrm{C} 1 \mathrm{~W}$ DCBs limited to a single frequency. The DCB changes show a very regular pattern, sole exceptions are missing changes on days 149/150 of 2017 for G069 and days 49, 56, and 57/2017 for G072.

Weekly mean DCB changes between time periods with and without flex power are plotted in Fig. 3. They were determined from the time interval 27 January 2018 until 7 April 2018 and range from 0.2 to $0.8 \mathrm{~ns}$ and show a very high repeatability with a standard deviation of 0.02 ns. For G066 and G068, no significant DCB changes could be detected.

No phase bias changes due to flex power could be detected in the difference of L1C-L1W phase observations. Likewise, the MW linear combination of L1 and L2 code and phase observations does not show any discontinuities related to this type of 

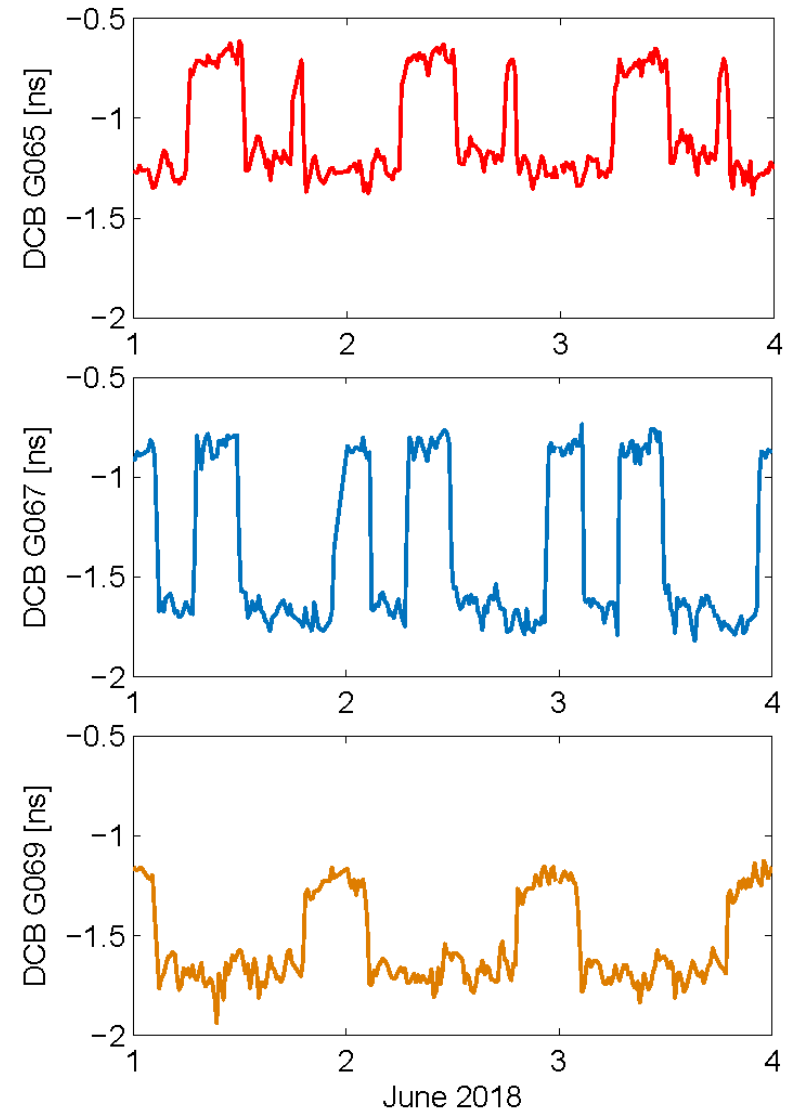

Fig. 2: High-rate C1C-C1W differential code bias estimates of three GPS Block IIF satellites.

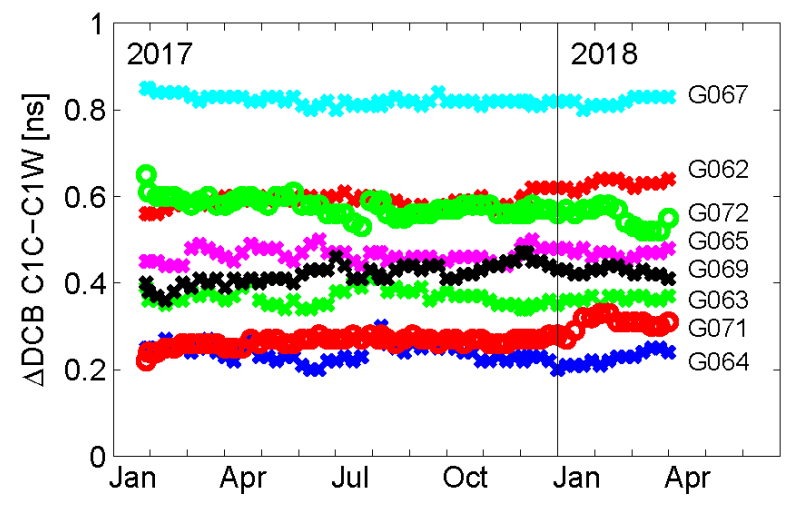

Fig. 3: Weekly mean C1C-C1W DCB changes due to flex power mode I.

flex power operations within the uncertainty level given by the contributions of thermal receiver noise and multipath.

\section{High-gain antenna}

Figure 4 shows the L1 spectral flux density of the Block IIF satellite G065 with and without flex power mode I. The red curve recorded on 1 June 2018 at 05:57 UTC represents the nominal signal transmission including $\mathrm{C} / \mathrm{A}-, \mathrm{P}(\mathrm{Y})-$, and M-code. The $1 \mathrm{MHz} \mathrm{C} / \mathrm{A}$-code introduces a sharp peak at $1575.25 \mathrm{MHz}$ whereas the broader, but $15 \mathrm{~dB}$ smaller, dome at the same center frequency is caused by the $10 \mathrm{MHz} \mathrm{P}(\mathrm{Y})$ code. Furthermore, the BOC $(10,5)$ binary offset carrier mod- ulation of the M-code introduces two prominent lobes at 1565 and $1585 \mathrm{MHz}$.

The dark blue curve was recorded 5 minutes later after the switch to flex power mode I. Here, the M-code lobes have vanished and the smaller sidelobes of the $\mathrm{P}(\mathrm{Y})$-code at 1560 and $1590 \mathrm{MHz}$ become visible. One can also see that the C/A- and $\mathrm{P}(\mathrm{Y})$-code flux density is slightly increased.

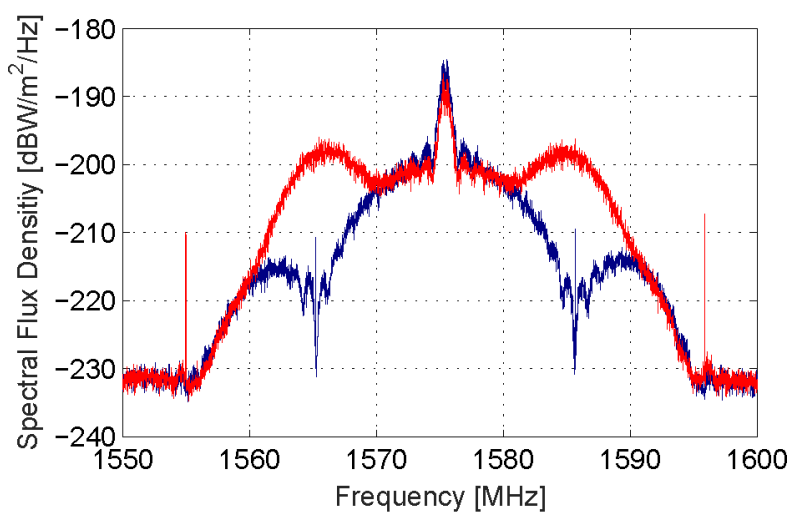

Fig. 4: L1 spectral flux density of the GPS Block IIF satellite G065 on 1 June 2018. Red: nominal transmission including M-code at 05:57 UTC. Dark blue: flex power mode I without M-code transmission at 06:02 UTC.

The effect of the flex power activation on the total L1 transmit power is illustrated in Fig. 5. It shows the Equivalent Isotropically Radiated Power (EIRP), i.e., the product of the actual transmit power and the line-of-sight dependent antenna gain (Seybold, 2005) for three different passes of G065 over the Weilheim ground station. The elevation dependency of the measured EIRP is caused by the characteristics of the satellite transmit antenna (Steigenberger et al., 2018). October 2016 marks nominal signal transmission including C/A-, $\mathrm{P}(\mathrm{Y})-$, and $\mathrm{M}$-code. June 2018 represents a pass with transition from nominal transmission including M-code to flex power mode I without M-code. A reduction in EIRP of about $0.6 \mathrm{~dB}$ can be seen at an elevation of $28^{\circ}$ in Weilheim. The April 2018 EIRP measurements refer to flex power mode II that will be discussed in the next section.

The contributions of individual L1 signal components to the total transmit power of two sample satellites are listed in Table 2 for the normal signal transmission as well as the flex power mode I. During normal operation, an interplex modulation is employed for the $\mathrm{C} / \mathrm{A}-, \mathrm{P}(\mathrm{Y})-$, and $\mathrm{M}$-code. In addition to the three signals, an intermodulation (IM) product is required to maintain a constant power envelope (Betz, 2016; Partridge and Dafesh, 2001). The IM product does not provide useful navigation information but contains roughly $20 \%$ or, equivalently, $16 \mathrm{~W}$ of the total L1 transmit power. During flex power mode, a pure quadrature phase shift keying (QPSK) modulation with two orthogonal signal components is employed. Despite a slightly reduced total power, the resulting C/A- and $\mathrm{P}(\mathrm{Y})$ signals are about $2.5 \mathrm{~dB}$ stronger in flex power mode $\mathrm{I}$ than in nominal mode as a result of the M-code and IM deactivation. 


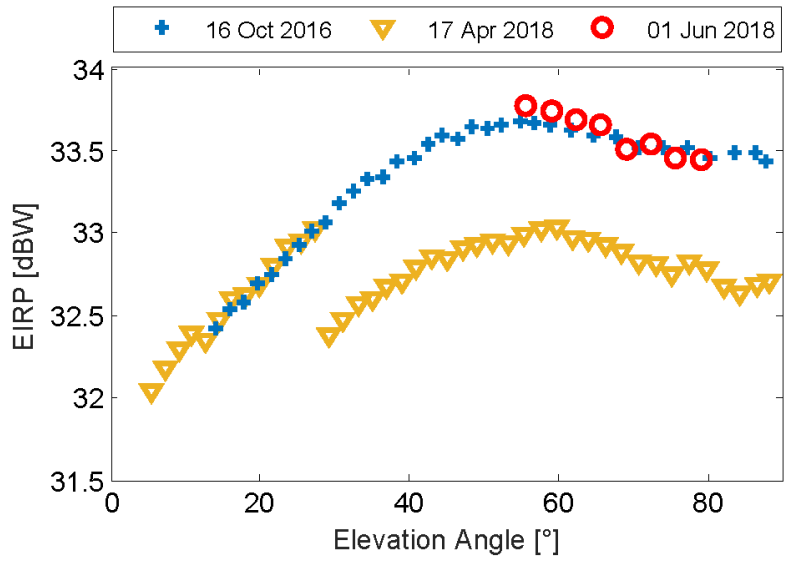

Fig. 5: L1 Equivalent Isotropically Radiated Power (EIRP) of G065. 16 October 2016: nominal transmission including C/A-, P(Y)-, and M-code; 17 April 2018: flex power mode II; 1 June 2018: transition from nominal to flex power mode I resulting in an EIRP reduction of about $0.6 \mathrm{~dB}$.

Table 2: Total L1 transmit power and fractional contributions of C/A-, $\mathrm{P}(\mathrm{Y})-, \mathrm{M}$-code and intermodulation product (IM) for two Block IIF satellites. SVN denotes the Space Vehicle Number.

\begin{tabular}{llccccc}
\hline \multirow{2}{*}{ SVN } & Mode & \multicolumn{6}{c}{ L1 } \\
\cline { 3 - 7 } & & C/A & P(Y) & M & IM & Total \\
\hline \multirow{2}{*}{ G063 } & Normal & $30 \%$ & $15 \%$ & $35 \%$ & $20 \%$ & $78 \mathrm{~W}$ \\
& Flex I & $66 \%$ & $34 \%$ & - & - & $62 \mathrm{~W}$ \\
\multirow{2}{*}{ G065 } & Normal & $31 \%$ & $16 \%$ & $34 \%$ & $19 \%$ & $80 \mathrm{~W}$ \\
& Flex I & $66 \%$ & $34 \%$ & - & - & $67 \mathrm{~W}$ \\
\hline
\end{tabular}

\section{Mode II: 13-17 April campaign}

In mid-April 2018, a flex power campaign with four days duration was conducted by the GPS control segment for GPS Block IIR-M and IIF satellites. The observed $\mathrm{P}(\mathrm{Y})$-code $\mathrm{C} / \mathrm{N}_{0}$ of all healthy GPS Block IIR-M and IIF satellites increased on 13 April 2018 between 12:00 and 18:00 UTC. They returned to normal levels on 17 April 2018 between 16:00 and 23:00 UTC. In contrast to the military $\mathrm{P}(\mathrm{Y})$-signal, no $\mathrm{C} / \mathrm{N}_{0}$ changes were observed in this flex power mode for the civil L1 C/A and L2C signals.

\section{Carrier-to-noise density ratio}

Between 13 and 17 April 2018, a C/N $\mathrm{N}_{0}$ increase of about $10 \mathrm{~dB}$ could be observed for semi-codeless $\mathrm{P}(\mathrm{Y})$ tracking on $\mathrm{L} 1$ and L2 (S1W and S2W) for seven Block IIR-M and twelve Block IIF satellites. For the unhealthy Block IIR-M satellite G049, no flex power could be observed. The satellite-specific start and end dates are listed in Table 3. Figure 6 illustrates the time period with increased $\mathrm{C} / \mathrm{N}_{0}$ of semi-codeless $\mathrm{P}(\mathrm{Y})$ tracking for the IGS station Hartebeesthoek (South Africa). In addition to the elevation-dependent $\mathrm{C} / \mathrm{N}_{0}$ variations, a $10 \mathrm{~dB}$ increase for about four days is obvious.
Table 3: Satellite-specific time periods for GPS flex power from $\mathrm{S} 2 \mathrm{~W} \mathrm{C} / \mathrm{N}_{0}$ analysis. The start times refer to 13 April 2018, the end times to 17 April 2018. Both times are given in UTC.

\begin{tabular}{llllll}
\hline SVN & PRN & SatCat & Block & Start & End \\
\hline G048 & G07 & 32711 & IIR-M & $16: 28$ & $23: 02$ \\
G050 & G05 & 35752 & IIR-M & $14: 04$ & $16: 07$ \\
G052 & G31 & 29486 & IIR-M & $15: 00$ & $16: 32$ \\
G053 & G17 & 28874 & IIR-M & $14: 31$ & $16: 50$ \\
G055 & G15 & 32260 & IIR-M & $11: 55$ & $17: 53$ \\
G057 & G29 & 32384 & IIR-M & $13: 00$ & $15: 59$ \\
G058 & G12 & 29601 & IIR-M & $15: 02$ & $20: 25$ \\
G062 & G25 & 36585 & IIF & $13: 14$ & $18: 35$ \\
G063 & G01 & 37753 & IIF & $18: 35$ & $20: 12$ \\
G064 & G30 & 39533 & IIF & $16: 24$ & $21: 31$ \\
G065 & G24 & 38833 & IIF & $12: 26$ & $19: 02$ \\
G066 & G27 & 39166 & IIF & $16: 34$ & $18: 18$ \\
G067 & G06 & 39741 & IIF & $12: 06$ & $22: 35$ \\
G068 & G09 & 40105 & IIF & $15: 19$ & $22: 41$ \\
G069 & G03 & 40294 & IIF & $15: 39$ & $21: 44$ \\
G070 & G32 & 41328 & IIF & $14: 21$ & $22: 46$ \\
G071 & G26 & 40534 & IIF & $15: 48$ & $17: 04$ \\
G072 & G08 & 40730 & IIF & $12: 31$ & $19: 41$ \\
G073 & G10 & 41019 & IIF & $13: 53$ & $17: 56$ \\
\hline
\end{tabular}

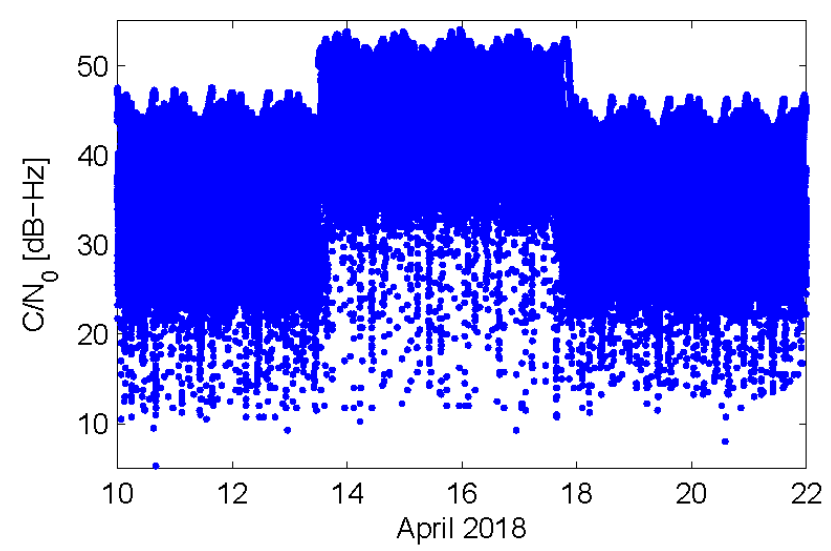

Fig. 6: $\mathrm{S} 2 \mathrm{~W} \mathrm{C} / \mathrm{N}_{0}$ time series of all healthy Block IIR-M and IIF satellites in mid April 2018 (flex power mode II) for the IGS Station Hartebeesthoek (HRAG00ZAF) considering observations above a $0^{\circ}$ elevation threshold.

For the Block IIR-M satellites, the increase of the $\mathrm{C} / \mathrm{N}_{0}$ appeared instantaneously whereas for the Block IIF satellites, an intermediate $\mathrm{S} 1 \mathrm{~W} / \mathrm{S} 2 \mathrm{~W} \mathrm{C} / \mathrm{N}_{0}$ level could be detected with a duration of 25-126s. The high-gain antenna analysis revealed that this effect is related to the consecutive deactivation of the M-code on L1 and L2. However, L1 and L2 power changes can not be separated and only the total $\mathrm{L} 1+\mathrm{L} 2$ power change can be measured from $\mathrm{C} / \mathrm{N}_{0}$ in the semi-codeless tracking (Woo, 2000). The increased $\mathrm{C} / \mathrm{N}_{0}$ values persisted four days and returned to normal on 17 April 2018. For the $\mathrm{P}(\mathrm{Y})$ power reduction, the intermediate $\mathrm{C} / \mathrm{N}_{0}$ levels for the Block IIF satellites had in general a duration of $30-136$ s except for G062 with 514 s.

The response to the $\mathrm{P}(\mathrm{Y})$-code power reduction in terms of measured $\mathrm{C} / \mathrm{N}_{0}$ is illustrated in Fig. 7 for three different GNSS 

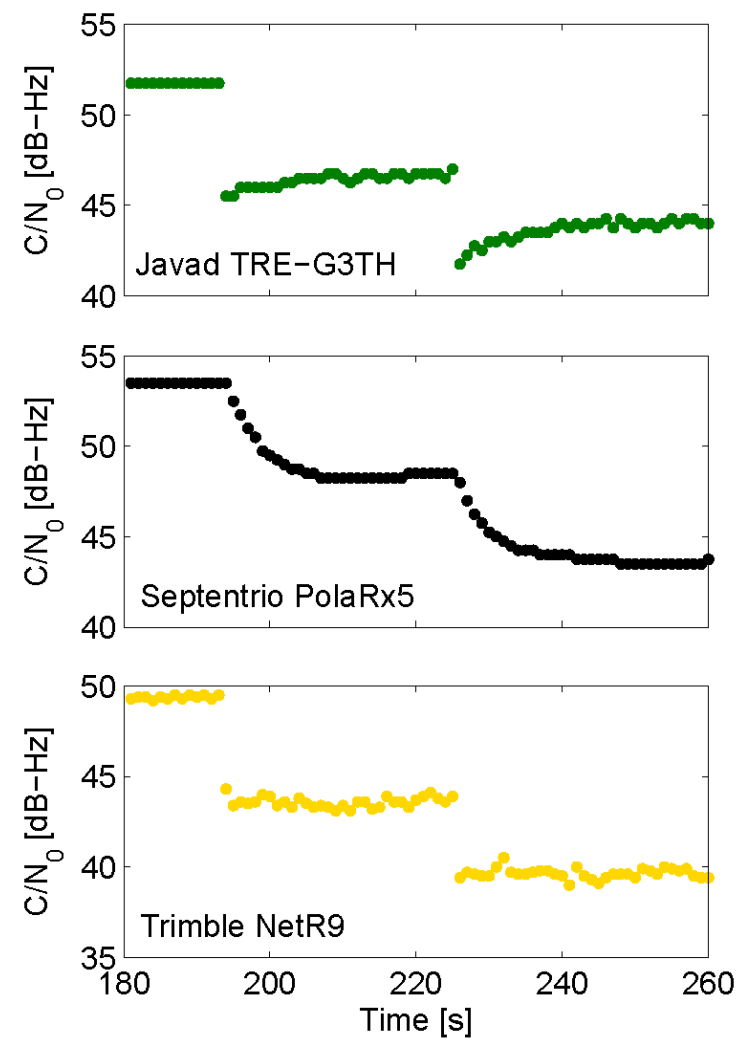

Fig. 7: High-rate $1 \mathrm{~Hz} \mathrm{~S} 2 \mathrm{~W} \mathrm{C} / \mathrm{N}_{0}$ time series of the GPS Block IIF satellite G071 (PRN G26) for three different GNSS receivers operated at GSOC on 17 April 2018. The reference epoch is 17:00 UTC.

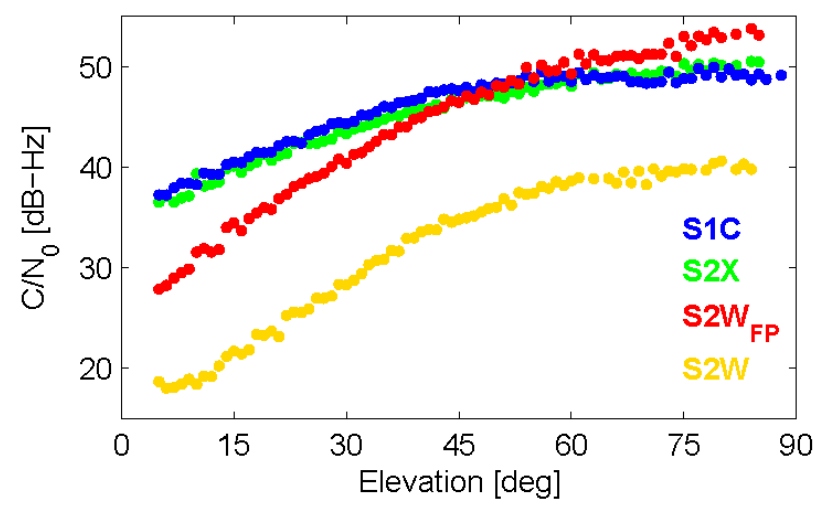

Fig. 8: Averaged $\mathrm{C} / \mathrm{N}_{0}$ in $1^{\circ}$ bins for the IGS station Calgary on 14 April 2018. S1C stands for the L1 C/A C/ $\mathrm{N}_{0}$ and S2X for the $\mathrm{L} 2 \mathrm{C} \mathrm{C} / \mathrm{N}_{0}$ of all GPS satellites. S2W denotes the $\mathrm{C} / \mathrm{N}_{0}$ of the semi-codeless L2 $\mathrm{P}(\mathrm{Y})$-code tracking. The index FP marks satellites with flex power.

receiver types jointly connected to the same GNSS antenna in Oberpfaffenhofen, Germany, via an antenna splitter. All receivers consistently indicate a two-step power adjustment with $\mathrm{C} / \mathrm{N}_{0}$ changes of about $5 \mathrm{~dB}$ and $4 \mathrm{~dB}$, respectively. The overall $9 \mathrm{~dB} C / \mathrm{N}_{0}$ change in the semi-codeless $\mathrm{P}(\mathrm{Y})$-code tracking corresponds to an average power change of $4.5 \mathrm{~dB}$ of the individual $\mathrm{P}(\mathrm{Y})$-code signal components on L1 and L2.

Figure 8 shows the $\mathrm{C} / \mathrm{N}_{0}$ averaged in $1^{\circ}$ elevation bins for the L1 C/A-code (S1C) of all GPS satellites, the L2C signal
(S2X) of all Block IIR-M and IIF satellites, and the $\mathrm{C} / \mathrm{N}_{0}$ of the $\mathrm{P}(\mathrm{Y})$-code for satellites with $\left(\mathrm{S} 2 \mathrm{~W}_{\mathrm{FP}}\right)$ and without $(\mathrm{S} 2 \mathrm{~W})$ flex power for the IGS station Calgary (UCALO0CAN, Canada). The $\mathrm{C} / \mathrm{N}_{0}$ measurements for the civil L1 C/A and the L2C signals remain essentially unaffected by the mode II flex power. Differences between $\mathrm{S} 2 \mathrm{~W}$ and $\mathrm{S} 2 \mathrm{~W}_{\mathrm{FP}}$ are slightly elevationdependent and vary between 9 and $14 \mathrm{~dB}$ with a mean value of $12 \mathrm{~dB}$. Starting with an elevation of about $50^{\circ}, \mathrm{S} 2 \mathrm{~W}_{\mathrm{FP}}$ outperforms S1C and S2X.

\section{Code and phase biases}

Daily C1C-C1W DCB estimates of all GPS satellites for April 2018 are given in Fig. 9. DCB changes up to $0.8 \mathrm{~ns}$ are visible for flex power mode II compared to earlier and later days. Note that flex power mode I is active for Block IIF satellites before April 13 and after April 17. However, the respective short-term DCB changes (see Fig. 2) are not resolved in the daily DCB estimates of Fig. 9. For this type of flex power, DCB discontinuities can also be seen on the L2 frequency. C2W-C2L DCBs are given in Fig. 10 as an example but the behavior of the $\mathrm{C} 2 \mathrm{~W}$ $\mathrm{C} 2 \mathrm{~S}$ and $\mathrm{C} 2 \mathrm{~W}-\mathrm{C} 2 \mathrm{X}$ DCBs is very similar. The maximum DCB change due to flex power mode II on L2 is $0.4 \mathrm{~ns}$.

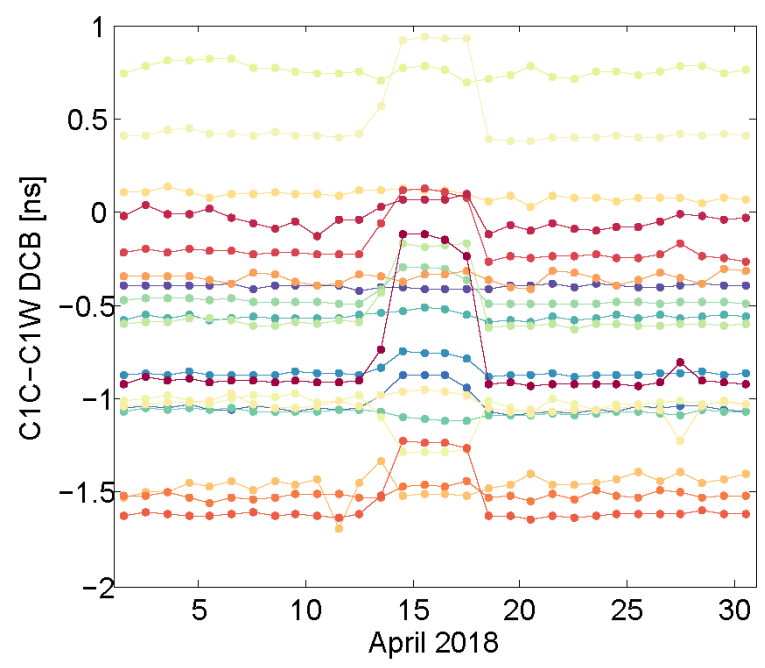

Fig. 9: Daily C1C-C1W differential code bias estimates of GPS Block IIR-M and IIF satellites with flex power mode II in April 2018.

Similar to the mode I flex power discussed in the previous section, no changes in L1 and L2 intra-frequency carrier phase biases could be observed upon activation and deactivation of mode II flex power. Also, no discontinuities of the MW combination exceeding the natural level of noise and multipath errors could be identified. As such, the flex power activation is considered to be free of adverse impacts on ambiguity resolution as used in precise point positioning or relative navigation methods.

\section{High-gain antenna}

At the end of the mid-April flex power campaign, seven Block IIR-M and IIF satellites with flex power were observed for about one hour each with the Weilheim high-gain antenna. Two of these surveys directly caught the transition from flex power mode II to nominal operation. The spectral flux density 


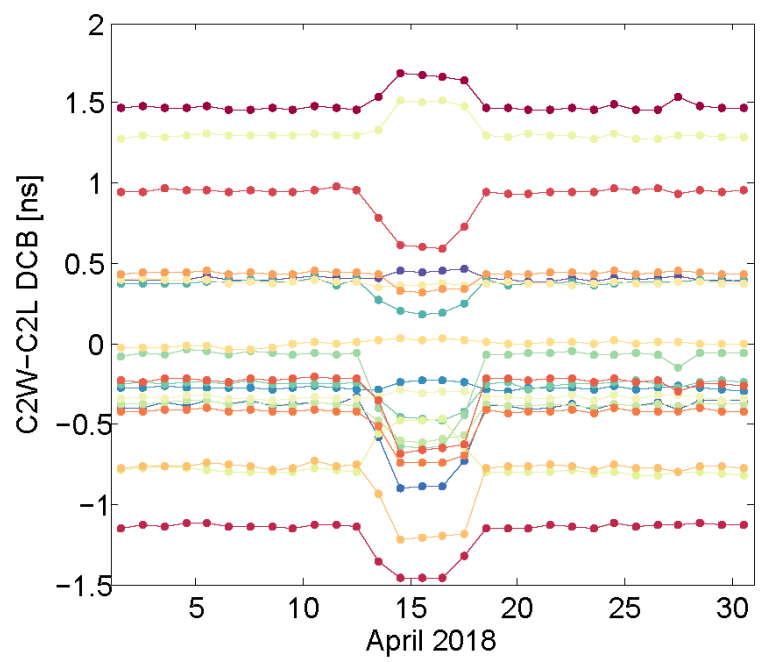

Fig. 10: Daily C2W-C2L differential code bias estimates of GPS Block IIR-M and IIF satellites with flex power mode II in April 2018.
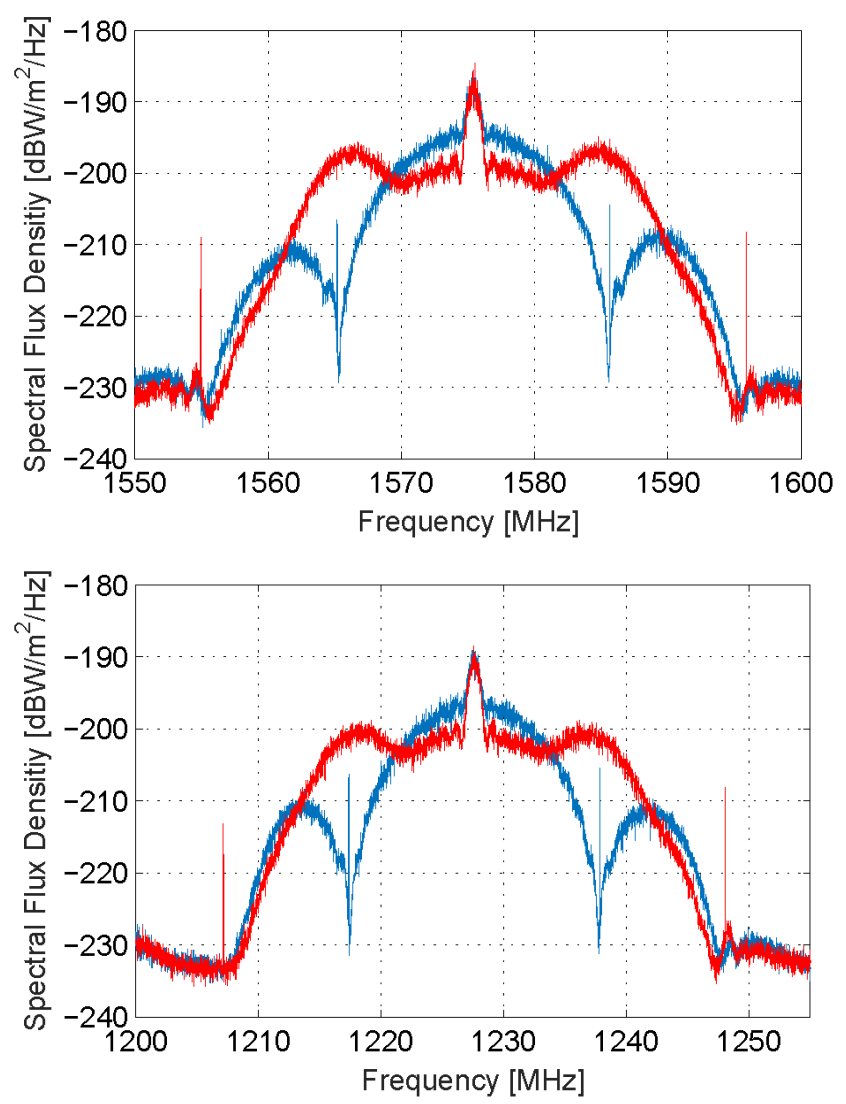

Fig. 11: Spectral flux density of the Block IIF satellite G071 with nominal transmission (red) and flex power mode II (blue) on 17 April 2018: L1 (top) and L2 (bottom).

on L1 and L2 for the Block IIF satellite G071 with nominal signal transmission and with flex power mode II is shown in Fig. 11. The spectral flux density of the L1 C/A-code signal at 1575.42 MHz basically stays constant whereas the L1 P(Y) flux density increases by roughly $5 \mathrm{~dB}$. Likewise, the power of the civil L2C signal at $1227.60 \mathrm{MHz}$ remains unaltered, while the $\mathrm{L} 2 \mathrm{P}(\mathrm{Y})$ power increases upon flex power activation. The lobes
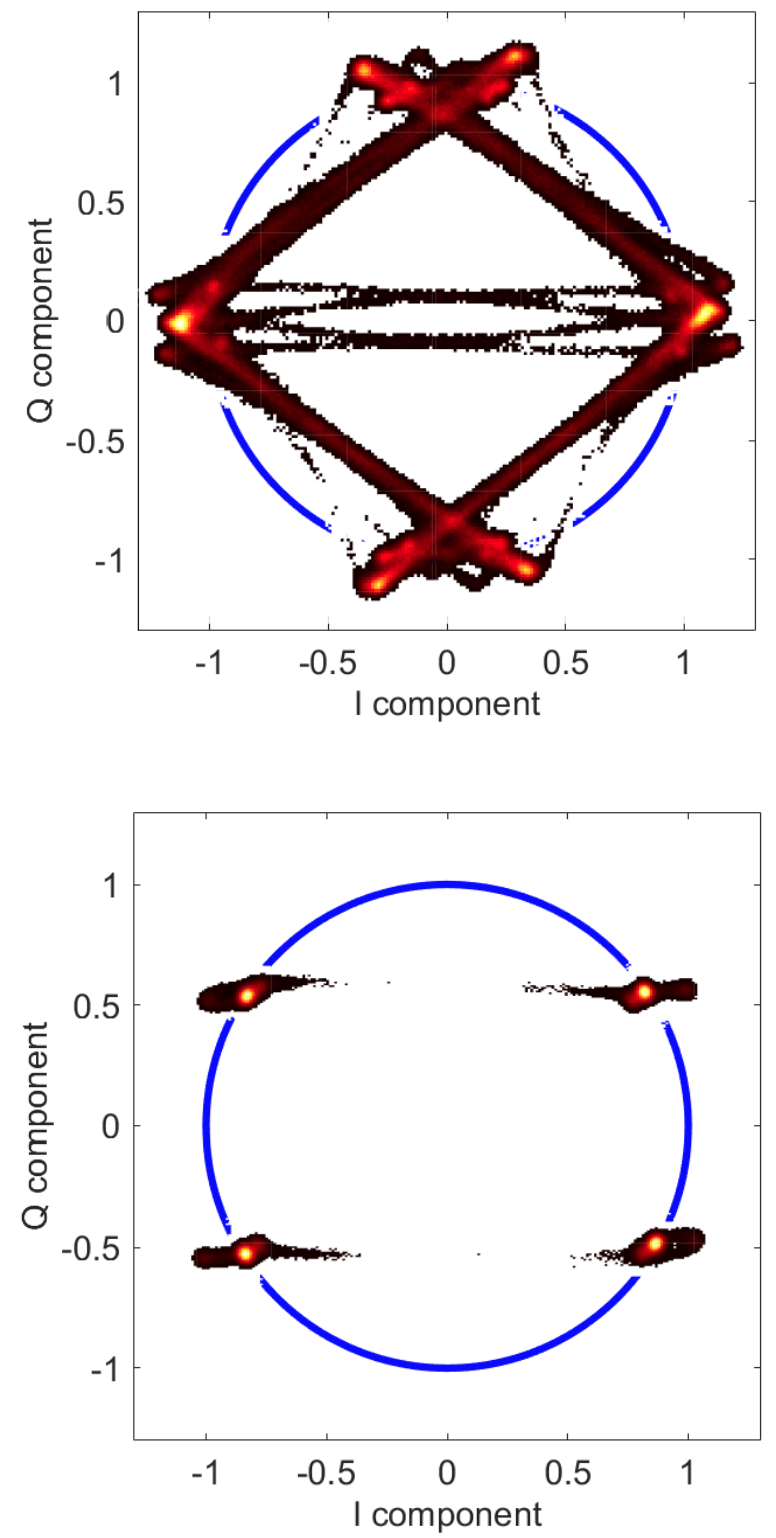

Fig. 12: L1 constellation plots for G071: nominal transmission including M-code (top) and flex power transmission without M-code (bottom). The unit circles represent the measured transmit power (33.8 dBW EIRP), which remains unaltered at flex power activation.

at $\pm 10 \mathrm{MHz}$ relative to the center frequency, which are characteristic for the BOC $(10,5)$ modulation of the M-code vanish on L1 and L2, which indicates that M-code is completely deactivated during flex power mode II on both frequencies.

For L1, this is further illustrated in the IQ constellation plots of Fig. 12, which show the distribution of in-phase (I) and quadrature $(\mathrm{Q})$ channel components in the modulated signal during nominal (top) and flex power operation (bottom). The interplex modulation involving three signal components $(\mathrm{C} / \mathrm{A}$, $\mathrm{P}(\mathrm{Y}), \mathrm{M})$ as well as the intermodulation product results in nominally eight stationary points for purely rectangular chip shapes (Partridge and Dafesh, 2001). In practice, the peak points in the IQ diagram do not coincide rigorously with the unit circle corresponding to the actual transmit power, but exhibit notable 
Table 4: Transmit power changes due to flex power on 17 April 2018. Average values of G070 and G071 are given.

\begin{tabular}{|c|c|c|c|c|c|c|c|c|c|c|c|}
\hline \multirow[t]{2}{*}{ SVN } & \multirow[t]{2}{*}{ Mode } & \multicolumn{5}{|c|}{ L1 } & \multicolumn{5}{|c|}{ L2 } \\
\hline & & Total & C/A & $\mathrm{P}(\mathrm{Y})$ & M & IM & Total & L2C & $\mathrm{P}(\mathrm{Y})$ & M & IM \\
\hline \multirow[t]{2}{*}{ G065 } & Normal & $80 \mathrm{~W}$ & $31 \%$ & $16 \%$ & $34 \%$ & $19 \%$ & $76 \mathrm{~W}$ & $30 \%$ & $24 \%$ & $25 \%$ & $21 \%$ \\
\hline & Flex II & & $69 \%$ & $31 \%$ & - & - & & $71 \%$ & $29 \%$ & - & - \\
\hline \multirow[t]{2}{*}{ G071 } & Normal & $77 \mathrm{~W}$ & $33 \%$ & $17 \%$ & $32 \%$ & $18 \%$ & $59 \mathrm{~W}$ & $31 \%$ & $24 \%$ & $25 \%$ & $20 \%$ \\
\hline & Flex II & & $69 \%$ & $31 \%$ & - & - & & $71 \%$ & $29 \%$ & - & - \\
\hline
\end{tabular}

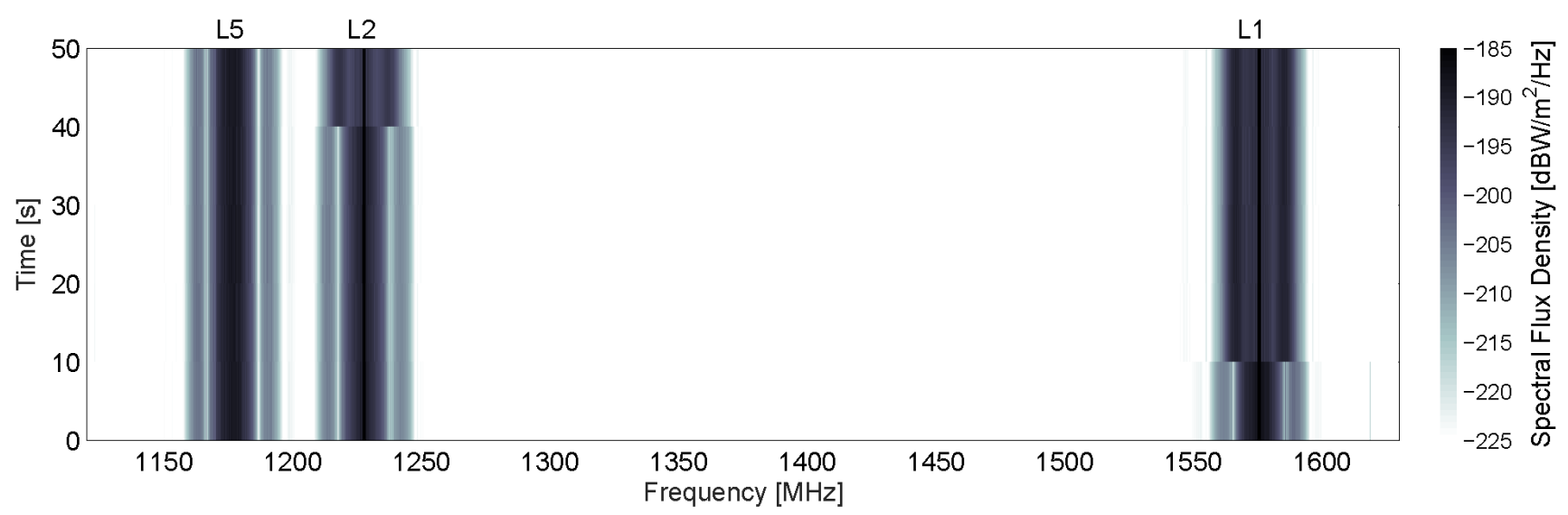

Fig. 13: Waterfall diagram of G071 illustrating the transition from flex power to normal operation including M-code transmission on 17 April 2018. The spectral flux density measured with a spectrum analyzer connected to the Weilheim $30 \mathrm{~m}$ antenna is shown. The reference epoch is 17 April 2018, 17:02:15 UTC.

distortions. These relate to the fact that the actual chip shapes deviate significantly from an ideal rectangular pulse and substantial time is spent in the individual state transitions.

Numerical values for the $\mathrm{C} / \mathrm{A}$ - and $\mathrm{P}(\mathrm{Y})$-code power of two dedicated satellites are listed in Table 4. In contrast to flex power mode I, the total transmit power stays constant. This can also be seen in Fig. 5 where the curve of October 2016 with nominal transmission and June 2018 during flex power mode III have the same L1 EIRP level. Whereas the power levels of the civil L1 C/A and L2C signals essentially remain constant, the $\mathrm{P}(\mathrm{Y})$-code power increases by $6 \mathrm{~dB}$ on $\mathrm{L} 1$ and $5 \mathrm{~dB}$ on $\mathrm{L} 2$. Fractions of individual signal components agree within $2 \%$ for the two satellites given in Table 4 which is well below the measurement accuracy.

A time series of spectral flux density measured with a spectrum analyzer connected to the high-gain antenna is given in Fig. 13. The power measurements were recorded with $10 \mathrm{~s}$ sampling. One can see that the L5 signal remains unchanged whereas the L1 and L2 signals show the shifted reactivation of the M-code at 10 and $40 \mathrm{~s}$, respectively, as already indicated by the $\mathrm{C} / \mathrm{N}_{0}$ analysis.

\section{Mode III: 27 April, 1 and 4 May campaigns}

On 27 April, 1 May, and 4 May 2018, three other flex power campaigns could be recognized but with different characteristics than the previous ones. All campaigns started at 2:00 UTC sharp and ended at 13:00 UTC sharp, but this time, the Block IIR-M satellites G048/G053 and the Block IIF spacecraft
G064/G068 did not participate. $\mathrm{C} / \mathrm{N}_{0}$ changes in the order of 9 to $11 \mathrm{~dB}$ are visible for S1W and S2W. For selected Block IIR-M satellites, a 2 to $3 \mathrm{~dB} \mathrm{C} / \mathrm{N}_{0}$ reduction is present for the time periods with increased S1W/S2W. However, these changes are difficult to detect due to noisy $\mathrm{C} 1 \mathrm{C} \mathrm{C} / \mathrm{N}_{0}$ measurements superimposed by pronounced multipath effects at many stations. No $\mathrm{C} / \mathrm{N}_{0}$ changes could be observed for the different tracking modes of the L2C signal, namely S2S/S2L/S2X.

The ground tracks of the satellites with flex power mode III during time periods with increased $\mathrm{C} / \mathrm{N}_{0}$ are plotted in Fig. 14 . Except for G067 whose ground track is located south of Africa, all satellites show a good visibility from the United States. Except for the start and end times, the switch times are shifted by $-4^{\min } \times 4=-16^{\mathrm{min}}$ for the first and the second campaign and by $-4^{\min } \times 3=-12^{\min }$ for the second and third campaign to produce the same ground coverage.

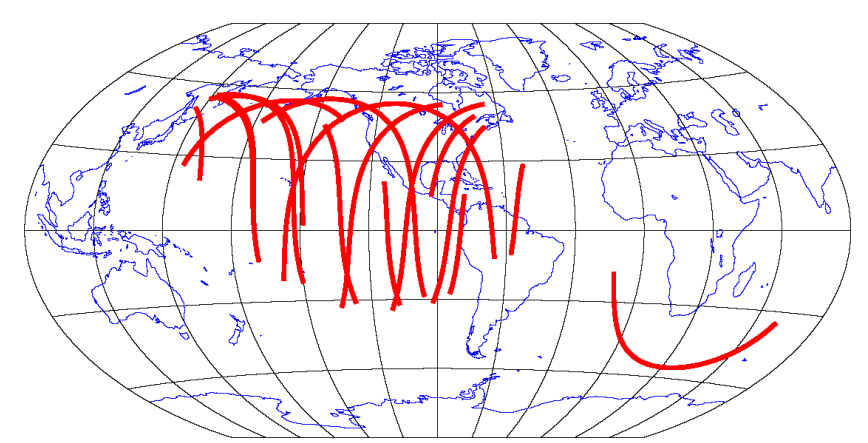

Fig. 14: Groundtracks of GPS satellites with increased $\mathrm{C} / \mathrm{N}_{0}$ on 4 May 2018. 
C1C-C1W DCB changes with an order of magnitude of 0.2 to $0.8 \mathrm{~ns}$ are visible for most Block IIF satellites and two Block IIR-M spacecraft (G057 and G058). For C2W-C2L, only five satellites show DCB changes above the noise level (G063, G070 - G073) and for C2W-C2X only two satellites (G070 and G073). No DCB changes could be detected for C2W-C2S.

Likewise, no discontinuities are discernible in $\mathrm{L} 1$ and L2 intra-frequency phase biases, i.e., L1C-L1W, L2S-L2W, L2L-L2W, and L2X-L2W, as well as the MW linear combination. Unfortunately, no high-gain antenna measurements are available for the mode III flex power campaigns. However, due to the size of the $\mathrm{C} / \mathrm{N}_{0}$ changes and the presence of L2 DCB changes, it is reasonable to assume that the M-code on L1 and L2 was disabled for this type of flex power.

\section{Summary and conclusions}

Three different types of flex power operations could be observed in 2017/2018. The regional flex power mode I is active on all healthy Block IIF spacecraft since February 2017. This mode only affects L1 and shifts parts of the M-code power to the C/Aand $\mathrm{P}(\mathrm{Y})$-code whereas the total transmit power on L1 is reduced. These power changes are visible in S1C and S1W/S2W $\mathrm{C} / \mathrm{N}_{0}$ observations as well as high-rate $\mathrm{C} 1 \mathrm{C}-\mathrm{C} 1 \mathrm{~W}$ DCB estimates.

In mid-April 2018, a continuous 4-day flex power occurred that affected both, the L1 and L 2 frequency bands. For this type of flex power, the L1 C/A-code and L2C power remains essentially constant and the M-code power is transferred to the $\mathrm{P}(\mathrm{Y})$ code on both frequencies, L1 and L2. The total transmit power in both bands remains constant. Flex power mode II increases the $\mathrm{S} 1 \mathrm{~W} / \mathrm{S} 2 \mathrm{~W} \mathrm{C} / \mathrm{N}_{0}$ by roughly $11 \mathrm{~dB}$ and introduces discontinuities of up to 0.8 and $0.4 \mathrm{~ns}$ for L1 and L2 intra-frequency DCBs, respectively.

Finally, three short regional flex power campaigns with a different pattern than the first one were observed in April/May 2018. Each of the three 11-hours campaigns results in increased $\mathrm{S} 1 \mathrm{~W} / \mathrm{S} 2 \mathrm{~W} \mathrm{C} / \mathrm{N}_{0}$ values which are partly accompanied by reduced S1C values. As no high-gain antenna measurements are available for flex power mode III, one can only speculate that also for this type of flex power, M-code was disabled on both frequencies and power was mainly redistributed to the military $\mathrm{P}(\mathrm{Y})$ signal.

None of the three flex power modes was found to affect phase biases, neither on L1, nor on L2. However, DCB estimates are affected by discontinuities of up to $0.8 \mathrm{~ns}$. As these discontinuities appear at subdaily time scales that are not reflected in daily DCB estimates, they are potentially relevant for pseudorange users, e.g., for MW ambiguity resolution. However, analysis of the MW linear combination for the different types of flex power did not reveal discontinuities above the noise level. Therefore, one can assume that high precision GPS users are likely not affected by flex power in an adverse sense.

Although NANU 2017005 announcing configuration changes on the GPS satellites is officially not included in the "Current Operational Advisories" (https://www.navcen. uscg.gov/?pageName=currentAdvi sory\&format=txt), flex power mode I is still enabled at the time of writing (August 2018). Therefore, further flex power tests like the mode II and III campaigns might be expected in the future. Although the recent flex power campaigns had no negative impact for precise GPS users, such effects cannot be excluded for possibly different types of flex power.

\section{Acknowledgements}

We'd like to acknowledge the efforts of the IGS/MGEX station operators and data centers.

\section{References}

Barker BC, Betz JW, Clark JE, Correia JT, Gillis JT, Lazar S, Rehborn KA, Straton JR (2000) Overview of the GPS M code signal. In: ION NTM 2000, Anaheim, pp 542-549

Betz J (2016) Engineering Satellite-Based Navigation and Timing - Global Navigation Satellite Systems, Signals, and Receivers. Wiley-IEEE, DOI 10.1002/9781119141167

Defense Science Board (2005) The future of the Global Positioning System. Tech. rep., Office of the Under Secretary of Defense For Acquisition, Technology, and Logistics, URL https: //www .acq.osd.mil/dsb/reports/2000s/ ADA443573.pdf

Dow JM, Neilan RE, Rizos C (2009) The International GNSS Service in a changing landscape of Global Navigation Satellite Systems. J Geod 83(3-4):191-198, DOI 10.1007/s00190008-0300-3

Edgar C, Goldstein DB, Bentley P (2002) Current constellation GPS satellite ground received signal power measurements. In: ION NTM 2002, San Diego, pp 948-954

Falletti E, Pini M, Presti LL (2011) Low complexity carrier-to-noise ratio estimators for GNSS digital receivers. IEEE Transactions on Aerospace and Electronic Systems 47(1):420-437

Fisher SC, Ghasemi K (1999) GPS IIF - the next generation. Proc IEEE 87(1):24-47, DOI 10.1109/5.736340

Håkansson M, Jensen ABO, Horemuz M, Hedling G (2016) Review of code and phase biases in multi-GNSS positioning. GPS Solut 21(3):849-860, DOI 10.1007/s10291-016-0572-7

Hauschild A (2017) Combinations of observations. In: Springer Handbook of Global Navigation Satellite Systems, Springer International Publishing, pp 583-604, DOI 10.1007/978-3319-42928-1_20

Hauschild A, Montenbruck O (2016) A study on the dependency of GNSS pseudorange biases on correlator spacing. GPS Solut 20(2):159-171, DOI 10.1007/s10291-014-0426-0

InsideGNSS Team (2010) IS-GPS-200E: Flexing power and fixing phrase ambiguities. InsideGNSS URL http://insidegnss . com/is-gps-200e-flexingpower-and-fixing-phrase-ambiguities/

International GNSS Service (IGS) RINEX Working Group and Radio Technical Commission for Maritime Services Special Committee 104 (RTCM-SC104) (2015) RINEX, The Receiver Independent Exchange Format, Version 3.03. Tech. rep., URL ftp://igs.org/pub/data/format/ rinex303.pdf

IS-GPS-200J (2018) Interface specification IS-GPS-200: Navstar GPS Space Segment/Navigation User Segment Interfaces. Tech. rep., URL https://www.gps.gov/ technical/icwg/IS-GPS-200J.pdf 
IS-GPS-705E (2018) Navstar GPS Space Segment/User Segment L5 Interfaces. Tech. rep., Global Positioning System Directorate Systems Engineering \& Integration, URL https : //www.gps.gov/technical/icwg/ISGPS-705E.pdf

Jimenez-Banos D, Perello-Gisbert J, Crisci M (2011) The measured effects of GPS Flex power capability collected on Sensor Station data. In: 2010 5th ESA Workshop on Satellite Navigation Technologies and European Workshop on GNSS Signals and Signal Processing (NAVITEC), DOI 10.1109/ NAVITEC.2010.5708073

Laurichesse D, Mercier F, Berthias JP, Broca P, Cerri L (2009) Integer ambiguity resolution on undifferenced GPS phase measurements and its application to PPP and satellite precise orbit determination. J Inst Navig 56(2):135-149, DOI 10.1002/j.2161-4296.2009.tb01750.x

Montenbruck O, Hauschild A, Steigenberger P (2014) Differential code bias estimation using multi-GNSS observations and global ionosphere maps. In: ION ITM 2014, Institute of Navigation, pp 802-812

Montenbruck O, Steigenberger P, Prange L, Deng Z, Zhao Q, Perosanz F, Romero I, Noll C, Stürze A, Weber G, Schmid R, MacLeod K, Schaer S (2017) The Multi-GNSS Experiment (MGEX) of the International GNSS Service (IGS) - achievements, prospects and challenges. Adv Space Res 59(7):16711697, DOI 10.1016/j.asr.2017.01.011

Partridge MD, Dafesh PA (2001) Code power measurement methodology for GPS Block IIR-M and IIF on-orbit test procedures. In: ION GPS 2001, Salt Lake City, pp 2764-2772

Rajan JA, Irvine J (2005) GPS IIR-M and IIF: Payload modernization. In: ION NTM 2005, San Diego, pp 508-514

Rajan JA, Tracy JA (2002) GPS IIR-M: Modernizing the Signalin-Space. In: ION GPS 2002, Portland, pp 1585-1594

Seybold JS (2005) Introduction to HF Propagation. Wiley

Steigenberger P, Hauschild A, Langley R (2017) US Air Force puts more power into GPS Block IIR-M C/A-code. GPS World 28(4):8-9

Steigenberger P, Thoelert S, Montenbruck O (2018) GNSS satellite transmit power and its impact on orbit determination. J Geod 92(6):609-624, DOI 10.1007/s00190-017-1082-2

Szilágyi B, Bar-Sever Y, Bertiger W, Romans L (2017) New methodology and operational service for near-real-time calibration of GNSS inter-signal biases. In: ION GNSS+ 2017

Thoelert S, Erker S, Meurer M (2009) GNSS signal verification with a high gain antenna - calibration strategies and high quality signal assessment. In: ION ITM 2009, Portland, pp 2896-2909

Thoelert S, Meurer M, Erker S (2012a) In-orbit analysis of antenna pattern anomalies of GNSS satellites. J Inst Navig 59(2):135-144, DOI 10.1002/navi.11

Thoelert S, Meurer M, Erker S, Montenbruck O, Hauschild A, Fenton P (2012b) A multi-technique approach for characterizing the SVN49 signal anomaly, part 2: chip shape analysis. GPS Solut 16(1):29-39, DOI 10.1007/s10291-011-0204-1

Thoelert S, Furthner J, Meurer M (2013) GNSS survey - signal quality assessment of the latest GNSS satellites. In: ION ITM 2013, San Diego, pp 608-615

Thoelert S, Montenbruck O, Meurer M (2014) IRNSS-1A: signal and clock characterization of the Indian regional navigation system. GPS Solut 18(1):147-152, DOI 10.1007/ s10291-013-0351-7
Thoelert S, Hauschild A, Steigenberger P, Langley R (2018) GPS IIR-M L1 transmit power redistribution: Analysis of GNSS receiver and high-gain antenna data. J Inst Navig DOI 10.1002/navi.250

Woo K (2000) Optimum semicodeless carrier-phase tracking of L2. J Inst Navig 47(2):82-99, DOI 10.1002/j.2161-4296. 2000.tb00204.x

Wu A (2002) Predictions and field measurements of the GPS Block IIR L1 and L2 ground powers. In: ION NTM 2002, San Diego, pp 931-938

Peter Steigenberger received his master and $\mathrm{PhD}$ degree in Geodesy from Technische Universität München (TUM) in 2002 and 2009, respectively. Currently, he is senior researcher at DLR's German Space Operations Center (GSOC). His research interests focus on GNSS data analysis, in particular precise orbit and clock determination of GNSS satellites and the evolving navigation systems Galileo, BeiDou, and QZSS.

Steffen Thoelert received his diploma degree in electrical engineering from the University of Magdeburg in 2002. In May 2006 he joined the Institute of Communications and Navigation at DLR Oberpfaffenhofen. His current research activities include signal quality monitoring, satellite payload characterization, system calibration, GNSS compatibility and interference aspects.

Oliver Montenbruck is head of the GNSS Technology and Navigation Group at DLR's German Space Operations Center, where he started work as a flight dynamics analyst in 1987. His current research activities comprise space-borne GNSS receiver technology, autonomous navigation systems, spacecraft formation flying, precise orbit determination, and multi-constellation GNSS. 